\title{
Glutaryl-CoA dehydrogenase deficiency
}

INSERM

\section{Source}

INSERM. (1999). Orphanet: an online rare disease and orphan drug data base. GlutarylCOA dehydrogenase deficiency. ORPHA:25

Glutaryl-CoA dehydrogenase (GCDH) deficiency (GDD) is an autosomal recessive neurometabolic disorder clinically characterized by encephalopathic crises resulting in striatal injury and a severe dystonic dyskinetic movement disorder. 